\section{(2) OPEN ACCESS}

\title{
Reproductive carrier screening: responding to the eugenics critique
}

\author{
Lisa Dive (10 , Ainsley J Newson
}

Sydney Health Ethics, The University of Sydney, Sydney, New South Wales, Australia

\section{Correspondence to}

Dr Lisa Dive, Sydney Health Ethics, The University of Sydney, Sydney, NSW 2006, Australia; lisa.dive@sydney.edu.au

An early draft of this paper was presented to colleagues at Sydney Health Ethics, The University of Sydney.

Received 18 February 2021 Accepted 13 June 2021

Check for updates

(C) Author(s) (or their employer(s)) 2021. Re-use permitted under CC BY-NC. No commercial re-use. See rights and permissions. Published by BMJ.

\begin{tabular}{|l|}
\hline To cite: Dive L, Newson AJ. \\
J Med Ethics Epub ahead of \\
print: [please include Day \\
Month Year]. doi:10.1136/ \\
medethics-2021-107343 \\
\hline
\end{tabular}

\begin{abstract}
Reproductive genetic carrier screening (RCS), when offered to anyone regardless of their family history or ancestry, has been subject to the critique that it is a form of eugenics. Eugenics describes a range of practices that seek to use the science of heredity to improve the genetic composition of a population group. The term is associated with a range of unethical programmes that were taken up in various countries during the 20th century. Contemporary practice in medical genetics has, understandably, distanced itself from such programmes. However, as RCS becomes more widespread, gains public funding and uses expanded gene panels, there are concerns that such programmes could be perceived as eugenic either in intent or outcome. The typical response to the eugenics critique of RCS is to emphasise the voluntary nature of both participating in screening and making subsequent reproductive choices. While safeguarding individuals' freedom to choose in relation to screening is essential, we consider this response inadequate. By examining the specific ethical wrongs committed by eugenics in the past, we argue that to avoid the perception of RCS being a form of eugenics it is essential to attend to the broader normative context in which reproductive decisions occur. Furthermore, ethical RCS programmes must recognise and respond to their potential to shift societal norms that shape individual reproductive choices.
\end{abstract}

\section{INTRODUCTION}

Reproductive genetic carrier screening (RCS) involves testing individuals or couples to determine their likelihood of having a child with certain autosomal recessive or X linked genetic conditions. RCS may be undertaken at different life stages, but it is usually offered to people of reproductive age. This paper focuses on population RCS which is offered to anyone regardless of their family history or ancestry, either before or during pregnancy. ${ }^{1}$ Australia is currently conducting a pilot programme in which 10000 couples will undergo RCS. ${ }^{2}$ Each member of the couple ${ }^{i}$ will be tested to determine their combined chance of having a child with a genetic condition. Several other countries are trialling or have implemented similar programmes, for example, the Netherlands ${ }^{3}$ and Israel. $^{4}$ Options available to couples who have an increased chance of having a child with a genetic condition include interventions to avoid the birth of an affected child,

${ }^{\mathrm{i}}$ The couple being tested need not be in a relationship or planning to raise the child together. RCS tests the intended genetic parents and so can be offered for many different family configurations. or that allow preparation for the birth of a child with the condition.

One significant ethical concern about RCS is that it may be perceived as being eugenic in intent or outcome. Broadly, 'eugenics' describes the collection of practices (political, social and medical) aimed at fostering desirable characteristics within a species by manipulating heredity. Genetic screening for reproductive purposes, often conducted in order to avoid the birth of a child with certain genetic conditions, has some commonalities with eugenics because it is likely to influence which people will be born, and seems to require some notion of which types of future people are more or less desirable. RCS for conditions that are very severe and/or life limiting is less likely to be subject to concerns related to eugenics. However, there is a trend towards increasingly large panels being proposed or used for RCS, particularly in programmes that report couple-based results. ${ }^{5}$ When more genes and conditions are included in screening, there is greater potential for the programme to be perceived as reflecting value judgements based in eugenic attitudes. Furthermore, factors such as variable expressivity of genetic changes add a dimension of complexity to the decisions that prospective parents are likely to face: not only might there be uncertainty as to how the genetic changes in their future child will manifest phenotypically, the way these changes will impact on quality of life is subject to socioenvironmental context and will be influenced by cultural and societal conceptions of disability and difference.

Although many governments in the early 20th century had departments concerned with improving the genetic stock of their population, the term 'eugenics' is most strongly associated with highly unethical activities undertaken under the Nazi regime in Germany. When some of these eugenic practices came to light following the Second World War, eugenics was widely condemned and many eugenic societies in other countries changed their names and adjusted their activities to distance themselves from the atrocities committed. As a result, there is now an understandable reluctance to acknowledge the potentially eugenic aspects of reproductive genetics, including RCS. Indeed, the unethical nature of many 20th-century eugenics programmes has rendered the concept deeply stigmatised to the point of being taboo.

Contemporary genetic medicine-and especially any interventions that relate to reproduction, such as RCS-has deliberately set itself apart from eugenics programmes of the past. However, many aspects of such practices can be described as eugenic in their aims or likely outcomes, in the sense that 
they will probably influence which future people will be born. Generally, the response to the eugenics critique of RCSoutlined below-is to emphasise individuals' and families' freedom to make their own choices with respect to undergoing screening and also their freedom to make whatever reproductive decisions they choose following the result. However, we consider that an adequate response to the eugenics critique also requires examination of the impacts of RCS at both societal and individual or family levels, and the interplay between them. A population screening programme is likely to influence social norms that provide context for the choices that individuals and families make. In addition, there is a perception that many individual choices in aggregate might slightly shift the composition of a population. While scientifically RCS is unlikely to make a significant difference to the genetic composition of a population, ${ }^{\text {ii }}$ there is a concern that even the perceived potential for such a shift might affect societal norms and attitudes (both positively and negatively).

It is important to examine the moral wrongs committed in the name of eugenics and to avoid replicating them. Yet, focusing on individual freedom or liberty risks a problematic neglect of the societal impact of population genetic carrier screening programmes. To this end, in this paper, we argue that it is important to attend to the perceived eugenic potential of RCS. In other words, there are at least two things needed to ensure RCS is ethically implemented as a population-wide programme. First, while it remains essential to safeguard the freedom of individual choices with respect to the programme, this should not take place while neglecting the societal norms that shape those individual choices. Second, the collective impact of the choices made must be recognised.

This paper is divided into four sections. First, we outline some features of eugenics and attempts to rehabilitate the concept. Next, we examine the effects that the 20th-century eugenics movement had — and continues to have-on how we approach population RCS. We then argue that it is important to attend to the potentially eugenic impacts of genetic screening programmes, before offering, in the final section, some suggestions as to how our recommendations might be enacted in practice.

\section{WHERE DID EUGENICS GO WRONG?}

Much has been written about the history and ethics of eugenics, so we will provide only a brief overview here. Our concern is to identify the aspects of eugenics that are ethically problematic, to determine whether any of these wrongs might be relevant to RCS programmes. The term 'eugenics' is derived from Greek and means 'well born'; its current usage was coined by Francis Galton in the 1880s to describe the application of the science of heredity for the benefit of humanity. ${ }^{6}$ Eugenics was defined by Galton as 'the science of improving stock' (p 17). Eugenics has strong negative associations due to its use in a range of statesponsored programmes (such as those we outline below) that sought to promote certain characteristics in future generations. In this section, we synthesise the ethical issues in past eugenic programmes to discern two of their most significant ethical

\footnotetext{
${ }^{i i}$ We recognise that, for example, prenatal screening for chromosomal trisomies has resulted in a reduction in birth rates of people with Down syndrome. However, a population genetic screening programme for autosomal recessive and $\mathrm{X}$ linked conditions is unlikely to have a significant impact on the rate of disability in the population. Much disability is not inherited, and even in cases where it is thought that Mendelian disease is important, only a modest reduction is likely.
}

wrongs: first, that they promoted a narrow concept of what constitutes an ideal person (thereby denying the prima facie moral equality of all humans); and second, that their methods demonstrated a disregard for the well-being of particular groups of people through their use of abhorrent practices that are now considered violations of basic human rights.

Eugenic strategies broadly fall into two groups: positive eugenics and negative eugenics. Positive eugenic approaches seek to improve the genetic composition of a population by encouraging reproduction, or certain kinds of reproductive choices, among certain groups of people considered desirable, or among people who possess certain desirable characteristics. Examples of eugenic initiatives in the USA include the 'fitter families' contests held at American fairs in the 1920s and the 'better babies' programme in Indiana. ${ }^{7}$ Both programmes aimed to identify 'superior' families in order to encourage them to procreate.

Negative eugenics focuses on preventing reproduction among people considered undesirable in some way, to the same (although misguided) end of benefiting the genetic make-up of the population as a whole. Interventions included many practices that would be considered grossly unethical today including segregation, restrictions on marriage, involuntary sterilisation and involuntary euthanasia. ${ }^{8}$ Most notorious are the eugenic practices of the Nazi regime in Germany around the mid-20th century, which were widely condemned. From initially seeking to promote reproduction among those displaying the desired Aryan traits, Nazi eugenics progressed to compulsory sterilisation and involuntary euthanasia for those who did not meet designated ideals for personhood. These horrific measures were applied to people from different ethnic groups such as members of the Jewish population, and also those who lived with mental illness or disability. ${ }^{9}$

Many commentators have written about past eugenics programmes and the atrocities committed in the name of improving the human race (eg, ref 7 8). The most well known were the programmes of Nazi Germany and the USA, but the eugenics movement was also prevalent in the UK and Australia. ${ }^{10}$ A common feature of eugenics programmes was that the identification of desirable and undesirable characteristics reflected simplistic and unscientific assumptions about the extent to which certain traits are determined by genetic variations. Characteristics that were thought to be genetically determined included intelligence (and its converse, termed 'feeble-mindedness'), poverty, mental illness, alcoholism and other personality and social characteristics. As such, eugenics programmes were typically grounded in an inaccurate or unrealistic type of pseudoscience that manifested as genetic determinism. ${ }^{11}$ While being grounded in unscientific assumptions does not necessarily make past eugenics programmes morally wrong, it does detract from their validity and is one of the potential points of distinction between such programmes and current practices in clinical and population genetics.

In attempting to locate exactly what it is that makes eugenics morally wrong, Wikler identifies five 'candidate wrongs'. ${ }^{12}$ Of the wrongs Wikler considers, those most relevant for our purposes are what he calls 'value pluralism' and 'collectivism'. The lack of value pluralism describes a commitment to a narrow notion of what constitutes a better kind of person, and a failure to reflect sufficient diversity. Collectivism refers to the prioritising of communal interests over those of individuals. Wikler argues that neither of these candidate wrongs-which we relate below to the ethical wrongs we consider most important-are necessary properties of eugenics programmes. He concludes that eugenics is not intrinsically wrong, and is actually a relatively 
trivial and benign proposition when understood as the application of genetic science to benefit humanity. The problems instead arise over definitions of the acceptable methods, and when commitments to value pluralism and social justice are not upheld.

Wikler is not alone in arguing that eugenics is not inherently wrong. Common features of such arguments include the ideas that seeking to improve the human population using the science of heredity is not necessarily bad, but that the problems with past eugenics programmes lay in specific features of those programmes, such as coercion by the state. Ethically troubling eugenics programmes also held very specific and narrow views of what constitutes a desirable person and generally reflected racial, economic and other social prejudices.

Another distinction that can be made among efforts to improve the genetic composition of a population is whether the programme is state enforced, or alternatively provides reproductive options while still allowing individual families to choose whether to participate. Several authors have therefore suggested that versions of the latter such as 'laissez-faire eugenics'13 or "liberal eugenics ${ }^{14}$ are ethically defensible. Such accounts emphasise the importance of individual freedom. Attempts to devise ethically acceptable eugenic strategies typically stipulate that no one ought to be obliged (or coerced, or encouraged) to participate, but that it should be a voluntary programme offered to families who wish to select their offspring. Agar, for example, distinguishes his proposed liberal form of eugenics from previous programmes in that it does not aim to limit some people's reproductive choices, but rather seeks to improve the range of reproductive options available to anyone who wishes to participate. Importantly, while he considers the state might have a role in regulating the use of reproductive technologies, it should not be seen as compelling people to take up the offer of eugenic intervention. Furthermore, he argues that a liberal eugenics programme should hold a pluralistic attitude to human excellence, and that these choices should be made by prospective parents rather than the state.

Further variations on ethically acceptable approaches to eugenics have been defended, including by Anomaly who extends "liberal eugenics ${ }^{15}$ to include additional interventions that explicitly seek to promote reproduction among certain types of people and discourage others from having children. He suggests that eugenic principles can be enacted via policies that are nevertheless compatible with individual liberty, and do not involve statesanctioned perspectives on what constitutes a more desirable person. ${ }^{15} \mathrm{He}$ advocates a suite of policies ranging from making contraception more accessible, offering genetic testing and counselling more widely, and a range of incentives and penalties such as paid parental leave, through to more ethically complex proposals such as parental licensing. Some of his suggestions raise some serious ethical concerns, such as the appropriateness of the state (or some authority) deciding that certain groups of people are more valuable for society and ought to be encouraged to reproduce, while other should be discouraged. Without committing too strongly to any particular course of action, Anomaly suggests that there are some policy measures that could promote 'eugenic choices' and that as a consequence, 'the outcome will likely be collectively beneficial'. While we will not engage directly with all of the underlying ethical commitments of Anomaly's position, positions like his and Agar's on liberal eugenics are arguably compatible with the individual liberties that some societies (in particular, Western liberal democracies) so highly value.

Based on the critiques of state-enforced eugenics and arguments in favour of potentially ethically acceptable liberal eugenics programmes, we discern that the two most serious wrongs of eugenics are (1) a narrow and prejudicial notion of what makes a future person more desirable; and (2) use of methods that fail to respect the well-being of all persons. The basis in simplistic or inaccurate assumptions about genetics further undermines the validity of eugenics, but is not necessarily a moral wrong. Our first wrong maps to Wikler's wrong of 'value pluralism', while our second wrong is set up by Wikler's wrong of 'collectivism'collectivism provides the justificatory condition for the inappropriate methods of ensuring the right kinds of people are born.

As others such as Wikler have discussed, it is possible to conceive of a eugenics programme that avoids these most serious ethical faults. Some, however, would also argue that the so-called 'new eugenics' remains as ethically problematic as the 'old eugenics ${ }^{16}$ and as such that the essential wrongs of eugenics we have identified need to be taken seriously. Either way, it seems that liberal or laissez-faire eugenics, while avoiding some of the worst human rights violations committed in the name of eugenics, are subject to critique. Therefore, programmes that are potentially eugenic either in their intent or outcomes understandably avoid using the term.

Importantly, however, a rejection of the term 'eugenics' does not amount to the same thing as avoiding eugenic practices. Indeed, such practices may be occurring under a different label even if individual liberty is emphasised. Therefore, regardless of whether the term is used, it is important to interrogate the ethics of selecting which future children will be born. In this paper, we are not primarily focused on the possibility of instituting an ethically acceptable version of eugenics. Rather, we are concerned with ensuring that RCS programmes are designed and implemented in such a way as to avoid the ethical wrongs committed by eugenics programmes in the past (even inadvertently, if not in intent). As such, in the next section, we examine the ongoing effects of past eugenic practices on RCS programmes, to critically analyse whether the response of emphasising individual liberty is adequate.

\section{THE LEGACY OF EUGENICS FOR RCS}

Previous atrocities committed in the name of eugenics have had significant consequences for the field of clinical genetics and for narratives around reproductive interventions. There is a justifiably deep stigma attached to the term 'eugenics' due to its association with state-sponsored programmes that were abhorrent in the prejudiced attitudes that motivated them, in addition to their basis in inaccurate understandings of genetic inheritance and the role of genotypes in determining phenotypes. Eugenics at its peak could be understood as part of 'sociopolitical... attempts to improve the population's genetic profile'. ${ }^{17}$ While much of the scientific underpinning of 20th-century eugenics has been debunked, the movement remains an influential chapter in the history of genetics. As a result of this history, any genetic practices that can influence which people are born need to be distinguishable from eugenics. While we do not consider that contemporary RCS programmes commit any of the ethical wrongs that plagued problematic eugenics movements of the 20th century (discussed in the previous section), the practice remains subject to the critique that it is seeking to shape the genetic future of human society. In this section, we examine how RCS programmes have typically been characterised in order to distance the practice from eugenics.

The development of genetic medicine has been closely intertwined with the discipline of genetic counselling. This is in 
part to safeguard patients ${ }^{\text {iii }}$ rights and interests in light of the legacy of eugenics. An explicit commitment to the ethos of non-directiveness was made in the 1960s in the USA. Clarke describes this term as the notion that genetic counselling should aim 'not to guide the patient ... to an outcome predetermined ... but instead to support the patient in reaching their own decisions $^{18}$ ( $p$ 543). While initially (for some) the goals of genetic counselling included preventing the birth of children affected by genetic conditions, by the 1980 s the troubling ethical implications of such an approach were more widely accepted. ${ }^{19}$ During that decade, the importance of non-directive genetic counselling was endorsed by a majority of medical geneticists in 17 different countries. $^{20}$

Embracing non-directiveness has thus been in part an explicit attempt to distance the contemporary practice of medical genetics from eugenics movements of the past. However, the ideal of non-directive genetic counselling has been questioned and reinterpreted in recent decades, on both theoretical and practical bases. ${ }^{182122}$ There are divergent opinions as to whether an evolved concept of non-directiveness has value as a reminder of the importance of avoiding eugenic practices. Generally, however, it is agreed that genetic professionals should not seek to influence reproductive choices, but rather should foster patients' autonomy by supporting them to adjust to information that is relevant to their decision-making. ${ }^{18}{ }^{19}$ While this is a valid response to the historical legacy of eugenics and genetic interventions-as well as reflecting and aligning with a broader movement in medicine away from paternalistic practice and towards a commitment to fostering patients' autonomy-it remains important to engage with the question of how contemporary medical genetics differs from eugenics.

A key distinction between RCS (and genetic medicine broadly) and eugenics is that the former is concerned with benefiting individuals, while the latter sought to improve the genetic composition of populations. However, when RCS is implemented as a publicly available programme it becomes important to consider its potential (and perceived) population-level effects. There are several significant critiques of such programmes that reference or respond to eugenics (see for example ref 23-25). The engenics critique is the objection that RCS is eugenics by another name, in intent if not potentially also in outcome, and therefore that it is morally objectionable. This objection was initially aimed at prenatal diagnostic testing, ${ }^{26}$ which enables the identification of a fetus with a genetic condition, allowing women or parents the option of terminating the pregnancy. The expressivist critique argues that such a practice expresses a discriminatory attitude towards the lives of people with a disability, namely that their lives are not valued, or are less valued. ${ }^{17242728}$ RCS, whether offered before or during pregnancy, is also susceptible to this critique. ${ }^{\text {iv }}$ This may be especially relevant for the preconception period, as the range of options to intervene (such as using donor gametes, avoiding pregnancy, undertaking preimplantation genetic testing (PGT)) is greater before a pregnancy is established. Effectively, if screening is undertaken prior to conception, as opposed to prenatally, then the decision to intervene to select a 'better' fetus-a choice that has potentially eugenic associations-is even easier to make than with prenatal diagnostic

\footnotetext{
iii We use 'patient' to denote someone having a genetic test. Alternative terms include 'client' and 'consultand'.

${ }^{\text {iv }}$ Alongside the expressivist critique, it is also worth noting (as we discuss later) that families of children with genetic conditions are among the strongest advocates for making RCS widely available.
}

testing or screening for chromosomal aneuploidies (typically conducted early in pregnancy). One of the concerns is that the aggregate of many such choices might express eugenic values, even if unintentionally.

The response to such objections typically involves stating explicitly that RCS aims to provide individuals or families with additional choices, and (if they wish) with information to support their decision-making. ${ }^{123}$ RCS is not in any way obligatory ${ }^{\mathrm{v}}$ but, rather, it seeks to foster the reproductive autonomy of couples and families who choose to participate in screening. One of the more prominent ways of distancing RCS from eugenics is to emphasise that eugenics programmes were state imposed and coercive, whereas RCS is voluntary. Potential participants are offered RCS and may decide for themselves whether the information it yields would be valuable for them in the context of their reproductive decision-making. This is a deliberate refocusing of the intervention from the societal to the individual (family) level.

On an individual or family level, RCS aims to prevent the occurrence of severe genetic conditions in future children. Such a goal would typically be based in a rationale of avoiding suffering $^{\text {vi }}$ in a child and/or their family, although more overt framings around responsible parenting have also been offered. ${ }^{30}$ However, the stigma attached to the notion of selecting future children is so pervasive that RCS is more typically framed in terms of providing couples with information to support their reproductive choices and reproductive autonomy. ${ }^{23} 3132$

In response, while we recognise the importance of ensuring the voluntary nature of RCS, we argue in the following section that it is nevertheless ethically problematic to neglect its population-level impacts. Particularly when it is offered at scale and publicly funded, RCS might be subject to the first of the two ethical wrongs we identified as committed by eugenics, namely adhering to a specific ideal of a better or more desirable (future) person. The expressivist critique of RCS holds that such programmes express a discriminatory attitude to the value of the lives of people living with genetic conditions or other disabilities. If prospective parents are offered screening to determine whether they have an increased chance of having a child with a genetic condition, this suggests that having such a child would be undesirable. It could be seen-and, for many, it is the casethat the purpose of RCS is to enable parents to choose not to have a child with a genetic condition. Such a message is less ethically fraught when the genetic conditions screened for are very severe or life limiting. ${ }^{\text {vii }}$ However, the increasing size of panels for RCS means that it becomes more likely that there will be people living with genetic changes that are detected by RCS. The existence of such a programme may send a message that the lives of people living with genetic conditions are less desirable or valuable than others. ${ }^{26}$ Indeed, Shakespeare points out

\footnotetext{
${ }^{\mathrm{v}}$ Some carrier screening programmes have employed more coercive measures, for example in Cyprus, where a carrier screening test for $\beta$ thalassaemia was required by the church prior to marriage. ${ }^{29}$

vi، 'Suffering' is an important, yet undertheorised, concept. A full exploration of the normative aspects of suffering is beyond the scope of this paper.

${ }^{\text {vii }}$ The severity of the genetic condition in question is connected with the ethical acceptability of programmes such as RCS since the desire to avoid the suffering associated with a very severe and life-limiting condition is widely accepted. There is, however, a significantly subjective element to severity which is very difficult to quantify, and a conceptual analysis of the concept of severity is beyond the scope of this paper.
} 
that while it is unhelpful to equate prenatal testing with eugenics (and the same could be said of RCS), it is nonetheless essential to pay attention to the sociocultural context in which reproductive decisions are made. ${ }^{27}$

\section{WHY WE SHOULD NOT DENY THE EUGENIC ASPECTS OF RCS}

Given the horrific actions of eugenicists of the past, it is appropriate to distance the contemporary practices of medical genetics from such approaches. We do not consider that contemporary RCS commits any of the ethical wrongs associated with eugenics programmes of the past (either intentionally or inadvertently). Emphasising the voluntariness of participation in RCS is one important way of distinguishing RCS from early eugenics programmes. However, various authors ${ }^{33} 34$ have argued for different ways in which eugenic attitudes persist through the application of contemporary genetic and reproductive technologies, including RCS. Harwood argues that while 'liberal eugenics' is focused on improving an individual or a family-as opposed to a whole society or a 'race' of people-the notion of selecting better future people remains a potentially eugenic exercise. ${ }^{34}$ Thus, in this section, we argue that in addition to a commitment to upholding reproductive autonomy, it is essential also to attend to the societal impacts of programmes such as RCS.

Typically, an approach based on the value of individual choice describes the goals of RCS in terms of reproductive autonomy: the programme is designed to foster this. Freedom of choiceboth in relation to participation in screening, and about what to do with results - is paramount. To a significant extent this approach addresses the second of eugenics' two ethical wrongs, in particular the use of unacceptably coercive methods. However, the first moral wrong, adherence to a view that some kinds of people are inherently better than others, might still be perpetrated, even if there is a commitment to ensuring free reproductive choices. Focusing exclusively on reproductive autonomy as the central aim for RCS overlooks its population-level impacts. Two interconnected effects are particularly important: one is the sociocultural factors that impact individual reproductive decision-making; the other is the population-level impact of RCS and its potential to shift social norms.

\section{Social context of reproductive decisions}

Societal norms about what kinds of people and families are more desirable can be highly influential in the private reproductive decisions that individuals and couples make. In particular, the way that society construes disability and difference, and a perception that participating in RCS is the responsible or right thing to do can effectively limit the (perceived) acceptable reproductive choices available to individuals.

Reproductive decisions are not made by purely rational individuals who have perfect information and the ability to act on it in a logical and self-interested way. Johnston and Zacharias ${ }^{35}$ point out that 'reproductive autonomy cannot exist without attention to context' ( $p$ S10). People will bring different values and perspectives, as well as different life experience to the decisions they need to make. Furthermore, wider social determinants like family context, cultural factors (including religion) and socioeconomic dimensions can influence the reproductive choices that are available to individuals and couples. ${ }^{36}$ Such contextual influences also play a role in how people will evaluate the different choices available to them. Here we explain three ways in which sociocultural factors shape reproductive choices: first, we explain how individual choices are influenced by societal norms; second, we outline the role of epistemic issues related to disability; and third, we show how perceived routinisation of RCS can shape the reproductive choices available to individuals and families.

First, viewing reproductive decisions purely as matters of individual choice neglects the sociocultural context in which those decisions are made. It is essential to pay attention to how societal norms might influence the way individuals and couples make their reproductive choices. Harwood argues that there is a 'eugenic mentality' in the way that reproductive technology is used to create offspring, and that this cannot be erased simply by 'labelling it private"34 ( $p$ 160). She points out that even if programmes such as RCS are neither state imposed nor coercive, they might still be eugenic in intent. The kinds of reproductive choices that parents make are likely to favour certain characteristics that are deemed desirable due to widely held socially constructed ideals, or structural factors that mean a person with certain characteristics will be more advantaged. Shifting the focus of eugenic choices to the private context of individuals and couples does not avoid the first fundamental wrong committed by eugenics, namely presuming that some people are inherently better than others. ${ }^{\text {viii }}$ The vision of what makes a particular (future) person better or more desirable is to a significant degree socially constituted, so it is not possible to escape the eugenics critique simply by emphasising the freedom of individuals or families to pursue their own reproductive choices. Prospective parents' private pursuit of their own 'vision of the good' ( $p$ 150) can still reflect (and entrench) social inequity. It should be noted that reproductive choices that seek to avoid a fatal or very severe genetic condition are less subject to the influence of social norms, as there is widespread acceptance of the rationale for avoiding the suffering associated with such a condition. However, due to the complexity of how genes influence disease, families may be faced with difficult decisions that involve a high degree of uncertainty with respect to what a genetic variant might mean for their future child. Such decisions are more likely to draw on socially informed understandings of what it would be like to live with different kinds of disability or difference.

Second, the sociocultural context that shapes reproductive decision-making also reflects epistemic norms with regard to how disability is understood. ${ }^{37}$ Some of the important objections to prenatal testing or preconception screening for genetic conditions draw in part on the social, as opposed to the biomedical model of disability. ${ }^{17}$ Where the biomedical model defines disability as a deviation from some specified norm, the social model of disability recognises that impairment involves both a physical and/or intellectual anomaly, but that the degree of disablement depends (to some extent) on the social and environmental responses to that impairment. Socioenvironmental factors can include both attitudes such as discrimination or acceptance, as well as practical elements such as wheelchair ramps and support for the hearing impaired in community facilities. This understanding of disability helps to show that initiatives like RCS could actually reduce the societal acceptance of and support for people with disability, especially if they lead to there being fewer people living with certain disabilities (and thus less need for particular socioenvironmental interventions).

If a condition is included on a panel for RCS this may send a message to prospective parents that it is important to know about and potentially to be avoided. While such a message might

\footnotetext{
viii There are, of course, many pragmatic considerations that influence prospective parents' reproductive choices, in addition to the more normative factors such as judgements about the relative value of different people.
} 
not be contentious in relation to conditions that are severe and/ or life limiting, there are other genetic conditions for which a negative message might be considered more controversial or discriminatory. It is atypical for the perspective of people who live with disability to be available to potential parents who are making decisions about a pregnancy that is affected by a particular condition. ${ }^{27}$ This reflects an epistemic dominance of the medicalised perspective which can be viewed as a form of testimonial epistemic injustice, since the lived experience of many conditions tends to be marginalised and less visible within the mainstream social understanding of such conditions. ${ }^{38}$ The epistemic imbalance in how we understand the relationship between genetic conditions and disability is an example of a specific contextual factor that can contribute to the potentially eugenic nature of the reproductive decisions that individuals and families make.

A third contextual factor that can have a significant influence on the way that individuals and families approach decisionmaking in relation to RCS is that a programme which is government funded and widely available can be perceived as being part of routine preconception (or prenatal) care. This is sometimes described as 'routinisation'. ${ }^{39}$ Routinisation can undermine freedom of choice in relation to participating in RCS. Such a freedom is one of the key factors that distinguish genetic screening from eugenics, and is also relevant to decisions made following prenatal diagnosis. If RCS is perceived as routine then the choice not to participate becomes more difficult to make. There is a balance to be achieved between making screening widely available, but avoiding coercion due to the perception that screening is routine. ${ }^{40}$

\section{Societal consequences of RCS}

Responding to the eugenics critique by emphasising individual freedom in relation to RCS also fails to recognise that programmes such as RCS will also have population-level impacts. Here we expand on the above discussion to outline three main ways that a widely offered RCS programme can shift those social norms that provide context for individuals and couples' reproductive decision-making. These are that: RCS programme design can contribute to routinisation and a perception that screening is the right thing to do; RCS can implicitly communicate particular ideas about what kinds of families or people are better or more desirable; and that over time, RCS might also shift the composition of society by reducing the number of people living with certain genetic conditions and that this will affect the way that disability is understood in its social context. In each of these ways, RCS has the capacity to influence the normative context within which private reproductive decisions are made.

As mentioned above, routinisation is the idea that RCS is part of routine care and it brings the implication that screening is the right thing to do. This perception can arise when RCS is offered to everyone, and as more and more people take up the offer. If a majority of people participate in screening and a government or payer considers it important enough to fund, then participation becomes a norm. Recognising this potential impact of RCS and its consequences is important to ensure there is a true commitment to upholding freedom of choice to participate in RCS.

A related potential effect of RCS is that how the programme is offered might implicitly communicate assumptions about what a normal, desirable or acceptable family is like. Simply by offering screening for certain conditions, there is a suggestion that there are valid reasons for taking steps to avoid having a child with those conditions and therefore that the condition is undesirable. As Harwood points out, such an attitude is a potential threat to the fundamental moral equality of all people. ${ }^{34}$ As we argued earlier, one of the ethical wrongs committed in the name of eugenics was the promotion of a narrow concept of what makes a person desirable. While the notion of a 'better' person is significantly shaped by social context, elements of programme design may also contribute. For example, both the selection of conditions to be screened for in RCS, and the ways that options for further interventions are offered and evaluated have the potential to normalise or reinforce certain attitudes and values. These all form part of the normative societal context that influences how individual couples will evaluate their reproductive options and make their decisions.

Finally, a consequence of a widely offered RCS programme is that, over time, the number of people born with the conditions screened for could decrease. The likelihood of such an outcome is based on the experience with prenatal screening for conditions like Down syndrome, ${ }^{41-43}$ as well as existing carrier screening initiatives. ${ }^{44}$ If there are fewer people living with disability and difference, then society may become less accepting and accommodating of people who live with genetic conditions. In other words, the widely accepted understanding of what makes a 'better' person might narrow over time. This normative drift is likely to influence the reproductive decisions that people make. However, it also has the potential to have an adverse effect on the well-being of people in our communities who live with disabilities.

\section{RESPONDING TO THE SOCIETAL IMPACTS OF RCS}

Our position is that reflecting on the elements that RCS has in common with historical eugenics programmes provides an opportunity to distinguish RCS from the unethical practices of the past. There are clear benefits to RCS and there is demand for such programmes both from communities living with the genetic conditions screened for and the health professionals who care for them, as well as from the public. ${ }^{25}$ However, there are benefits to reflecting on the history of population genetic screening to ensure the equitable impact of such programmes. Safeguarding freedom of choice and value alignment in RCS is certainly an important part of differentiating the practice from eugenics. Doing so can improve the quality of screening programme design, for example, by ensuring that potential participants are supported to understand RCS and to deliberate about whether it would be right for them. However, we consider that emphasising freedom of choice is an insufficient response. In this final section, we draw on our argument about acknowledging the potentially eugenic aspects of RCS to briefly sketch some positive suggestions regarding how a population-wide RCS programme can respond to the eugenics critique and mitigate its impact.

First, as outlined earlier, disability scholars have argued that regardless of whether it is an acknowledged aim of RCS, a programme that uses a large panel will impact on societal norms and the ways that communities respond to people who live with disabilities. To take this concern seriously, an ethical RCS programme needs to recognise the potential for reduced acceptance of disability and difference and pay attention to how health and disability are understood in the context of screening. This involves committing explicitly to an inclusive attitude to people who live with genetic conditions, and recognition of the epistemic injustices that contribute to how disability and difference are conceptualised. It is also essential that in conjunction with RCS, efforts are made to improve the socioenvironmental factors that can contribute to impairment and the lived experience of genetic difference. This might involve parallel 
programmes to address stigma as well as promoting social and environmental features that support people who are differently embodied to live full and flourishing lives wherever possible.

A second way that RCS can avoid contributing to stigma and disadvantage for people living with genetic conditions is to implement a careful process to identify the conditions screened for, informed by various perspectives including those of people affected by various genetic conditions. This might involve a decision to focus only on conditions that are severe or life limiting. ${ }^{5}$ Limiting screening to conditions that are known to result in significant suffering or early death is also less likely to convey an unfavourable view of the value of the lives of people who have disabilities. For some severe genetic conditions, among the strongest advocates for RCS are families affected by genetic conditions. ${ }^{25}{ }^{45}{ }^{46}$ However, genetic conditions that present on a spectrum, such as those with variable expressivity, pose a particular challenge for RCS. There is further work to be done to elaborate on the concept of severity (both in relation to variable expressivity and more generally) and the role it plays in population genetics.

Third, RCS must be designed and implemented in such a way that it does not exacerbate inequity and disadvantage, given its capacity to shift societal norms. Ways of ensuring an equitable RCS programme include making it affordable for everyone who wants it, and funding further reproductive interventions and supports if an increased chance result is returned. ${ }^{\text {ix }}$ Although we do not endorse her position, Daar draws attention to various inequitable barriers to access, arguing that lack of equitable access to assisted reproductive technologies (ART) is a form of 'new eugenics' since it promotes reproduction among those who conform to certain norms-such as being in a heterosexual partnership or a 'traditional' family structure-and favours those who can afford to pay for expensive procedures such as in vitro fertilisation (IVF). ${ }^{33}$ While it is debatable whether inequitable access to ART is eugenic in the sense of shifting the genetic composition of a population, Daar nevertheless makes an important point that such injustices can serve to entrench certain social norms. These norms might also be reinforced by RCS if people who receive an increased chance result are not offered support in pursuing ART if they wish.

Finally, to distance itself from eugenics, RCS must seek to avoid routinisation which can lead to a perceived pressure both to participate in screening and also to take steps to avoid the birth of an affected child. This is not a simple task and requires a multifaceted approach and recognition of the contextual factors that might constrain or otherwise influence the reproductive decisions that people make. Routinisation will be lessened if, as discussed earlier, the epistemic contributors to social conceptions of disability are broadened to include the perspectives of those who live with various conditions. In addition, those who choose not to participate in RCS should be supported in that choice. Crucially, too, parents who go on to have a child with a genetic condition should be able to access balanced information about living with that condition, and are likely to benefit from support to prepare for raising their child.

\section{CONCLUSION}

There is an uncomfortable perception that RCS has some elements in common with past eugenics programmes that are

\footnotetext{
${ }^{\mathrm{ix}}$ This may, for example, include offering funding for a certain number of IVF cycles with preimplantation genetic testing (PGT).
}

widely considered to have been unethical. Contemporary RCS makes efforts to emphasise the freedom of individual participants and the voluntary nature of participating in screening, as well as undertaking any further interventions following a screening result. Appropriately, RCS emphasises improved outcomes for families and does not aim to change the genetic composition of the whole population. However, we have argued that such an approach is inadequate because it neglects the potentially eugenic impacts of RCS at the societal level. RCS may indeed promote reproductive choice, but it also has the capacity to shift the norms that provide the context within which individual families make their reproductive decisions. Therefore, a robustly ethical RCS programme must acknowledge these potentially eugenic effects, and that there are a variety of strategies that can be incorporated into the design and implementation of RCS programmes to mitigate these impacts.

\section{Twitter Lisa Dive @lisadive and Ainsley J Newson @biomedethics}

Acknowledgements The authors kindly thank Nigel Laing, Martin Delatycki and Edwin Kirk for their feedback on this paper.

Contributors LD initially drafted the paper with intellectual input from AJN. Both authors reviewed, edited and rewrote sections of the paper. Both authors have reviewed and approved the final version, and have collaborated on the revisions and responses to reviewers.

Funding The Australian Reproductive Genetic Carrier Screening Project (Mackenzie's Mission) is funded by the Australian Government's Medical Research Future Fund as part of the Genomics Health Futures Mission (GHFM), grant GHFM73390 (MRFF-G-MM). The grant is administered by the Murdoch Children's Research Institute through Australian Genomics.

Competing interests None declared.

Patient consent for publication Not required.

Provenance and peer review Not commissioned; externally peer reviewed.

Open access This is an open access article distributed in accordance with the Creative Commons Attribution Non Commercial (CC BY-NC 4.0) license, which permits others to distribute, remix, adapt, build upon this work non-commercially, and license their derivative works on different terms, provided the original work is properly cited, appropriate credit is given, any changes made indicated, and the use is non-commercial. See: http://creativecommons.org/licenses/by-nc/4.0/.

\section{ORCID iDs}

Lisa Dive http://orcid.org/0000-0001-6655-5138

Ainsley J Newson http://orcid.org/0000-0002-3460-772X

\section{REFERENCES}

1 Henneman L, Borry P, Chokoshvili D, et al. Responsible implementation of expanded carrier screening. Eur J Hum Genet 2016;24(6):e1-12.

2 Dive L, Newson AJ. Ethical issues in reproductive genetic carrier screening. Med J Aust $2021 ; 214(4)$

3 Schuurmans J, Birnie E, van den Heuvel LM, et al. Feasibility of couple-based expanded carrier screening offered by general practitioners. Eur J Hum Genet 2019;27(5):691-700.

4 Singer A, Sagi-Dain L. Impact of a national genetic carrier-screening program for reproductive purposes. Acta Obstet Gynecol Scand 2020;99(6):802-8.

5 Kirk EP, Ong R, Boggs K, et al. Gene selection for the Australian Reproductive Genetic Carrier Screening Project ("Mackenzie's Mission"). Eur J Hum Genet 2021;29(1):79-87.

6 Galton F. Inquiries into human faculty and its development. 2nd edn. London: J.M Dent \& Co, 1883

7 Stern AM. Making better babies: public health and race betterment in Indiana, 19201935. Am J Public Health 2002;92(5):742-52.

8 Kevles D. In the name of eugenics: genetics and the uses of human heredity. Berkeley: University of California Press, 1985.

9 Robertson M, Ley A, Light E. The first into the dark. Broadway: UTS ePress, 2019.

10 Watts R. Beyond nature and nurture: eugenics in twentieth century Australian history. Aust J Polit Hist 1994;40(3):318-34.

11 Chousou D, Theodoridou D, Boutlas G. Eugenics between Darwin's Era and the Holocaust. Conatus 2019;4(2):171-203.

12 Wikler D. Can we learn from eugenics? J Med Ethics 1999;25(2):183-94.

13 Kitcher P. The lives to come: the genetic revolution and human possibilities. New York, USA: Simon \& Schuster, 1997. 
14 Agar N. Liberal eugenics: in defence of human enhancement. Oxford, UK: Blackwell Publishing, 2004.

15 Anomaly J. Defending eugenics. Monash Bioeth Rev 2018;35(1-4):24-35.

16 Sparrow R. A not-so-new eugenics. Harris and Savulescu on human enhancement. Hastings Cent Rep 2011;41(1):32-42.

17 Scully JL. Disability and the challenge of genomics. In: Gibson S, Prainsack B, Hilgartner $\mathrm{S}$, et al, eds. Routledge Handbook of genomics, health and society. London: Routledge, 2018: 186-94.

18 Clarke A. The evolving concept of non-directiveness in genetic counselling. In: Petermann HI, Harper PS, Doetz S, eds. History of human genetics. Cham: Springer, 2017.

19 Biesecker BB. Goals of genetic counseling. Clin Genet 2001;60(5):323-30.

20 Kessler S. Psychological aspects of genetic counseling: VII. thoughts on directiveness. J Genet Couns 1992;1(1):9-17.

21 Clarke A. Prenatal genetic screening: paradigms and perspectives. In: Harper PS, Clarke AJ, eds. Genetics, society and clinical practice. Oxford, UK: Bios Scientific Publishers, 1997: 119-40.

22 Weil J. Psychosocial genetic counseling in the post-nondirective era: a point of view. J Genet Couns 2003;12(3):199-211.

23 De Wert GMWR, Dondorp WJ, Knoppers BM. Preconception care and genetic risk: ethical issues. J Community Genet 2012;3(3):221-8.

24 Scully JL. Disability and genetics in the era of genomic medicine. Nat Rev Genet 2008:9(10):797-802.

25 Raz AE. Community genetics and genetic alliances: eugenics, carrier testing, and networks of risk. London: Routledge, 2009.

26 Asch A. Prenatal diagnosis and selective abortion: a challenge to practice and policy. Am J Public Health 1999;89(11):1649-57.

27 Shakespeare T. Choices and rights: eugenics, genetics and disability equality. Disabil Soc 1998;13(5):665-81.

28 Parens $E$, Asch A. Disability rights critique of prenatal genetic testing: reflections and recommendations. Ment Retard Dev Disabil Res Rev 2003:9(1):40-7.

29 Hoedemaekers R, ten Have H. Geneticization: the Cyprus paradigm. J Med Philos 1998;23(3):274-87

30 van der Hout S, Dondorp W, de Wert G. The aims of expanded universal carrier screening: autonomy, prevention, and responsible parenthood. Bioethics 2019;33(5):568-76.

31 de Jong $A$, de Wert GMWR. Prenatal screening: an ethical agenda for the near future. Bioethics 2015:29(1):46-55.

32 Munthe C. A new ethical landscape of prenatal testing: individualizing choice to serve autonomy and promote public health: a radical proposal. Bioethics 2015;29(1):36-45.
33 Daar J. The new eugenics: selective breeding in an era of reproductive technologies. New Haven: Yale University Press, 2017.

34 Harwood K. Which "New Eugenics" ? Expanding Access to Art, Respecting Procreative Liberty, and Protecting the Moral Equality of All Persons in an Era of Neoliberal Choice. Int J Fem Approaches Bioeth 2020;13(2):148-73.

35 Johnston J, Zacharias RL. The future of reproductive autonomy. Hastings Cent Rep 2017;47(Suppl 3):S6-11.

36 Ong R, Howting D, Rea A, et al. Measuring the impact of genetic knowledge on intentions and attitudes of the community towards expanded preconception carrier screening. J Med Genet 2018;55(11):744-52.

37 Rubeis G, Steger F. A burden from birth? Non-invasive prenatal testing and the stigmatization of people with disabilities. Bioethics 2019;33(1):91-7.

38 Scully JL. From "She Would Say That, Wouldn't She?" to "Does She Take Sugar?" Epistemic Injustice and Disability. Int J Fem Approaches Bioeth 2018;11(1):106-24.

39 Kater-Kuipers A, de Beaufort ID, Galjaard R-JH, et al. Ethics of routine: a critical analysis of the concept of 'routinisation' in prenatal screening. J Med Ethics 2018;44(9):626-31.

40 Clarke A. Genetic counselling. In: Ashcroft RE, Dawson A, Draper H, et al, eds. Principles of health care ethics. 2nd ed. Chichester, UK: John Wiley \& Sons, 2007: 427-34.

41 Collins VR, Muggli EE, Riley M, et al. Is Down syndrome a disappearing birth defect? J Pediatr 2008;152(1):20-4. e1.

42 Maxwell S, Bower C, O'Leary P. Impact of prenatal screening and diagnostic testing on trends in Down syndrome births and terminations in Western Australia 1980 to 2013. Prenat Diagn 2015;35(13):1324-30.

43 Morris JK, Alberman E. Trends in Down's syndrome live births and antenatal diagnoses in England and Wales from 1989 to 2008: analysis of data from the National Down syndrome cytogenetic register. BMJ 2009;339:b3794.

44 Massie J, Petrou V, Forbes R, et al. Population-Based carrier screening for cystic fibrosis in Victoria: the first three years experience. Aust N Z J Obstet Gynaecol 2009;49(5):484-9.

45 Boardman FK, Young PJ, Griffiths FE. Population screening for spinal muscular atrophy: a mixed methods study of the views of affected families. Am J Med Genet $A$ 2017; 173(2):421-34

46 Thomas LA, Lewis S, Massie J, et al. Which types of conditions should be included in reproductive genetic carrier screening? Views of parents of children with a genetic condition. Eur J Med Genet 2020;63(12):104075. 